\title{
FINALIDADES EDUCATIVAS ESCOLARES E ESCOLA SOCIALMENTE JUSTA: A ABORDAGEM PEDAGÓGICA DA DIVERSIDADE SOCIAL E CULTURAL
}

\author{
FINALIDADES EDUCATIVAS ESCOLARES Y ESCUELA SOCIALMENTE JUSTA: EL \\ ENFOQUE PEDAGÓGICO DE LA DIVERSIDAD SOCIAL Y CULTURAL
}

\author{
SCHOOL EDUCATIONAL PURPOSES AND SOCIALLY FAIR SCHOOL: THE \\ PEDAGOGICAL APPROACH OF SOCIAL AND CULTURAL DIVERSITY
}

\author{
José Carlos LIBÂNEO ${ }^{1}$ \\ Eliane SILVA ${ }^{2}$
}

RESUMO: O presente artigo aborda a relação entre diferentes visões de finalidades educativas escolares acerca da escola socialmente justa e o lugar que o atendimento à diversidade sociocultural ocupa nessas finalidades. O objetivo é trazer à discussão as implicações desse atendimento no plano pedagógico-didático na escola e nas salas de aulas. No primeiro tópico, busca-se estabelecer as relações entre finalidades educativas escolares, escola socialmente justa e diversidade sociocultural. No segundo, é destacada a relevância política e pedagógica dos estudos sobre diversidade, trazendo diferentes abordagens do tema em pesquisas no Brasil e em alguns países da América Latina. Finalmente, no terceiro tópico, é sugerida uma abordagem pedagógica da diversidade em uma escola socialmente justa na perspectiva do ensino voltado para o desenvolvimento humano.

PALAVRAS-CHAVE: Finalidades educativas escolares. Escola justa. Diversidade sociocultural. Processo de ensino-aprendizagem. Ensino para o desenvolvimento humano.

RESUMEN: Este artículo aborda la relación entre diferentes visiones de las finalidades educativas escolares sobre la escuela socialmente justa y el lugar que la atención a la diversidad sociocultural ocupa en estas finalidades. El objetivo es traer a la discusión las implicaciones de esta atención en el plan pedagógico-didáctico en la escuela y en las aulas. En el primero tópico, se busca establecer las relaciones entre las finalidades educativas escolares, la escuela socialmente justa y la diversidad sociocultural. En el segundo, se destaca la relevancia política y pedagógica de los estudios sobre diversidad, trayendo diferentes enfoques al tema en la investigación en Brasil y en algunos países de América Latina. Finalmente, en el tercer tema, se sugiere un enfoque pedagógico a la diversidad en una escuela socialmente justa desde la perspectiva de la enseñanza orientada hacia el desarrollo humano.

\footnotetext{
${ }^{1}$ Pontifícia Universidade Católica de Goiás (PUC Goiás), Goiânia - GO - Brasil. Professor no Programa de PósGraduação em Educação. Pós-Doutorado pela Universidade de Valladolid (UVA). ORCID: https://orcid.org/0000-0002-8105-2165. E-mail: libaneojc@uol.com.br

2 Pontifícia Universidade Católica de Goiás (PUC Goiás), Goiânia - GO - Brasil. Professora no curso de Pedagogia. Doutorado em Educação (PUC Goiás). ORCID: https://orcid.org/0000-0002-7638-1722. E-mail: elianeucg@bol.com.br
} 
PALABRAS CLAVE: Fines educativos escolares. Feria de la escuela. Diversidad sociocultural. Proceso de enseñanza-aprendizaje. Enseñanza para el desarrollo humano.

ABSTRACT: This article discusses the relationship between different views of school educational aims in a socially-just school and the place that occupies in them the care of sociocultural diversity, aiming to bring to the discussion the implications of this care in the pedagogical-didactic plan in the school and classes. The first topic seeks to establish the relationships between school educational aims, the socially-just school and sociocultural diversity. In the second, the political and pedagogical relevance of studies on diversity is highlighted, bringing different approaches to Brazilian and some countries in Latin American researches. Finally, the third topic suggests a pedagogical diversity approach in a sociallyjust school in a developmental teaching perspective.

KEYWORDS: School educational purposes. Fair school. Sociocultural diversity. Teachinglearning process. Teaching for human development.

\section{Introdução}

O texto propõe abordar a relação entre diferentes visões de finalidades educativas escolares sobre escola socialmente justa e destacar, numa dessas finalidades, o atendimento à diversidade sociocultural, visando juntar elementos de análise de suas implicações no plano pedagógico-didático na escola e nas aulas. A presença da diferença e da diversidade humana no ensino é um tema clássico da pedagogia, no entanto, os desdobramentos dessa questão no debate político e acadêmico nas últimas décadas trouxeram à tona diferentes formas de abordá-la política e pedagogicamente na organização escolar e no trabalho dos professores nas aulas. Argumentamos que esse debate tem aparecido de diferenciadas formas no Brasil e em alguns países da América Latina, em que se ressalta tanto o discurso político quanto o pedagógico, mas frequentemente subsumindo o pedagógico no político. Desse modo, pretende-se neste artigo por em destaque a relevância da dimensão pedagógico-didática da diversidade sociocultural numa visão de escola socialmente justa na perspectiva do ensino voltado para o desenvolvimento humano, sem desconsiderar as implicações fortemente políticas do tema. Neste sentido, em um primeiro momento intenciona-se estabelecer relações entre as finalidades educativas escolares, a escola socialmente justa e a diversidade sociocultural. No segundo ressalta-se a relevância política e pedagógica dos estudos sobre diversidade trazendo diferentes abordagens do tema na produção acadêmica brasileira e de alguns países da América Latina. Por fim, no terceiro momento, é proposta uma abordagem pedagógica da diversidade em uma escola socialmente justa na perspectiva do ensino voltado para o desenvolvimento humano. 


\section{Finalidades educativas escolares, escola socialmente justa e diversidade sociocultural}

A discussão acerca de uma escola socialmente justa está vinculada às definições de finalidades educativas escolares nos sistemas de ensino, ao destaque dado nessas definições à atenção à diversidade sociocultural e às formas de assegurar pedagogicamente, nas escolas, essa atenção. Algumas questões vêm à tona ao se considerar essas relações. Que noção de justiça educacional está por detrás das finalidades enunciadas? A busca pela justiça social na escola se resolve colocando a atenção à diversidade como finalidade educativa predominante? Ou esse atendimento à diversidade subordina-se a funções clássicas da escola voltadas para a formação cultural e científica dos alunos? A supervalorização da diferença pode levar a sacrificar o atendimento à igualdade? É possível pensar um tipo de ensino que assegure a todos os alunos aprender aquilo que é necessário aprender como condição da igualdade entre os seres humanos e, ao mesmo tempo, considerar a diversidade humana e social desses alunos no processo de ensino-aprendizagem? Tais perguntas mostram a relevância das finalidades educativas escolares e como seus enunciados se refletem na formulação de uma concepção de escola socialmente justa. Ao mesmo tempo, fornecem indicativos de que não é possível conceber uma escola justa sem se levar em conta a diversidade sociocultural e as formas de se lidar política e pedagogicamente com ela.

A questão das finalidades educativas escolares é crucial no quadro atual dos estudos sobre a educação pública, uma vez que dela decorrem outras implicações, entre elas os posicionamentos sobre as funções preponderantes das escolas. Estudos sobre finalidades educativas escolares que têm ocupado a atenção de pesquisadores estrangeiros (LENOIR et al., 2016; LESSARD; MEIRIEU, 2005; FIALA, 2007; NODDINGS, 2007; entre outros) e brasileiros (EVANGELISTA, 2014; LIBÂNEO, 2014; 2016; 2019; PESSONI, 2017; LIBÂNEO; FREITAS, 2018), trazem elucidações conceituais, fontes teóricas e estudos comparativos. Para Lenoir et al. (2016), a questão das finalidades educativas escolares é complexa e controversa. As nações têm hoje um interesse real pela escola, ela é vista como necessidade e, às vezes, como panaceia para os problemas da sociedade. No entanto, quando se trata da discussão de finalidades, surgem diferentes entendimentos dos conceitos de democracia ou justiça e sobre os usos deles, assim como de concepções acerca de objetivos, funções e formas de funcionamento das escolas.

Conforme os mesmos autores, as finalidades educativas escolares definem atribuição de sentido e de valor ao processo educativo, indicam orientações tanto explícitas quanto implícitas aos sistemas escolares, induzem ações nos planos empírico e operacional para as 
práticas de ensino-aprendizagem. As finalidades refletem, também, a noção de ser "educado" numa determinada sociedade conforme contextos sociais, culturais, políticos e, assim, determinam parâmetros pelos quais os agentes educativos fundamentam suas práticas na gestão de sistemas, nas escolas e salas de aula. A elaboração das finalidades ocorre no plano social e político em distintas instâncias institucionais, governamentais, empresariais, profissionais, associativas, expressando interesses e relações de poder em âmbito internacional e nacional e, no plano acadêmico, nos marcos das correntes filosóficas, sociológicas, psicológicas, etc., que vigoram no campo educacional de onde surgem teorias da educação. Especialmente no plano acadêmico, é oportuno mencionar os embates correntes no campo da educação acerca do papel social das escolas, de onde se originam acentuados dissensos em torno do significado de "qualidade de ensino", dificultando formas de luta política frente à clareza de finalidades e objetivos expressos nas políticas neoliberais para a educação (LIBÂNEO, 2011, 2018). Em consequência disso, Lenoir et al. (2016), com base em estudos comparativos em relação a vários países, apontam dilemas na definição de funções da escola: instrução ou socialização, de abertura ou controle, de educação geral ou qualificação profissional, de escolarização ou atendimento à diversidade sociocultural, de formação de valores conservadores individualistas ou valores coletivos de justiça, de solidariedade, autonomia. Presentemente, as finalidades educativas escolares estão fortemente vinculadas a agendas estabelecidas no plano da economia política global por meio de organismos e agências internacionais (EVANGELISTA, 2014), impondo aos sistemas de ensino a visão economicista em que a escola seria o lugar destinado somente à formação para o trabalho, visando habilidades e destrezas profissionais. Em contraposição a essa visão, educadores críticos confrontam-se na busca de princípios em torno de escola socialmente justa voltada para a emancipação humana.

A relação entre educação e justiça social é um tema presente nas mais diferentes concepções de finalidades educativas. Em busca de critérios de distribuição dos bens educativos, numa formulação bastante genérica, justiça social na escola seria garantir a todos os alunos uma base comum de conhecimentos e competências indispensáveis à preparação para um futuro profissional e obtenção de êxito na vida social. No entanto, essa formulação adquire significados muito diferentes conforme premissas filosóficas, sociológicas, pedagógica das finalidades educativas que lhe dão suporte. Três posicionamentos podem ser apontados como possíveis respostas às pretensões de justiça social na escola: a educação de resultados, a educação para a diversidade, a educação como desenvolvimento de capacidades humanas em articulação com a diversidade (LIBÂNEO, 2019). 
O primeiro posicionamento refere-se à educação de resultados, definida a partir de critérios econômicos, em que a escola visa fornecer conteúdos mínimos necessários ao trabalho e emprego, expressos em competências de tipo instrumental avaliados por testes padronizados, e um tipo de formação de atitudes e valores para contenção de conflitos sociais. Conforme o artigo $4^{\circ}$ da Declaração Mundial sobre Educação para todos (UNESCO, 1990), "a educação básica deve estar centrada na aquisição e nos resultados efetivos da aprendizagem, [...] daí a necessidade de definir, nos programas educacionais, os níveis desejáveis de aquisição de conhecimentos e implementar sistemas de avaliação de desempenho". Conforme já abordado em outros estudos (LEHER, 1998; ALGEBAILE, 2009; EVANGELISTA; SHIROMA, 2006; EVANGELISTA, 2014; dentre outros), a educação de resultados constituise parte da lógica das políticas de aliviamento da pobreza em que a escola é colocada como estratégia do Estado para solução de problemas sociais e econômicos que venham a afetar a ordem social e política. Garcia menciona que os termos "inclusão social" e "educação inclusiva" são encontrados nos documentos de organismos internacionais e nacionais em relação direta com as políticas educacionais orientadas para a redução da pobreza e atendimento a grupos "vulneráveis". Segundo a autora, "essa abordagem contribui com o processo de transformação do significado da expressão 'direitos coletivos' em "responsabilidades individuais" (GARCIA, 2014, p. 109). Em síntese, na perspectiva da educação de resultados, escola justa é a que distribui a todos um currículo "mínimo", tendo por base competências e habilidades mínimas para o trabalho, aferidas por testes padronizados, em associação com ações socioeducativas visando a socialização e integração social. O individuo é tomado como fator de produção econômica, desvinculado de suas condições sociais, culturais e materiais de vida, numa visão reducionista de formação humana.

O segundo posicionamento, que põe especial relevo na atenção às diferenças entre pessoas e grupos socioculturais, foi se firmando tanto com a ampliação da luta pelos direitos humanos quanto por movimentos culturais de afirmação da diferença entre os seres humanos e do direito à diferença. Segundo Candau (2011, p. 20), "as diferenças culturais invadem os espaços públicos e reivindicam seu reconhecimento e valorização", por exemplo, pelo acesso a oportunidades tanto educacionais quanto ao mercado de trabalho, pela representação nos espaços de tomada de decisões. A atenção à diferença como critério de justiça social apresenta-se em diferentes ênfases, mas tem como denominador comum a valorização das práticas sociais e culturais em que se ressaltam os temas da pluralidade de culturas, da diversidade cultural e da diferença. Numa posição mais extremada, uma visão pós-crítica tem 
como conceitos-chave a identidade e a diferença como elementos da subjetividade humana e a recusa de qualquer critério de universalidade próprio dos seres humanos. Com isso, no que diz respeito ao conhecimento, é posto relevo nas culturas particulares e nos pontos de vista dos sujeitos a partir dessas culturas.

Essa visão sociológica/intercultural de escola justa defende um currículo de experiências socioculturais em que se destacam as práticas de compartilhamento de diferentes valores e de solidariedade, o acolhimento da diversidade social e cultural, a constituição de identidades culturais. No entanto, à medida que são valorizadas mais as práticas sociais da experiência corrente do que as práticas propriamente pedagógicas, inclusive o acesso aos conteúdos científicos e culturais, essa visão tende a dissolver o foco no conhecimento e no desenvolvimento de capacidades intelectuais, condição de autonomia e de liberdade para a expansão de outras capacidades humanas, inclusive de "dar voz" aos direitos sociais. Em síntese, esta visão compreende que justiça social na escola acontece quando se oferece a todos um currículo diversificado, assentado em experiências educativas locais e cotidianas, focado em vivências socioculturais, num ambiente de acolhimento às singularidades dos alunos e à diversidade sociocultural.

O terceiro posicionamento corresponde à ideia de que a educação escolar mais justa é aquela que promove e amplia o desenvolvimento das potencialidades humanas, provendo os meios cognitivos e afetivos para os alunos alcançarem autonomia, liberdade, capacidade de participação e intervenção na realidade social. Nessa visão, a escola é uma das mais importantes instâncias de democratização da sociedade e de promoção de inclusão social, cabendo-lhe propiciar os meios da apropriação dos saberes sistematizados constituídos socialmente, como base para o desenvolvimento das capacidades intelectuais e a formação da personalidade. Considera-se, ademais, que a escola recebe sujeitos em sua diversidade social e cultural e, assim, faz-se necessário ligar os conteúdos escolares às práticas socioculturais e institucionais (e suas múltiplas relações) nas quais os alunos estão inseridos. Decorre desta visão o currículo de formação cultural e científica articulado com a diversidade sociocultural. A qualidade social e pedagógica da escola começa com o empenho pela igualdade social ao buscar reduzir a diferença de níveis de escolarização e educação entre os grupos sociais, já que a superação das desigualdades sociais guarda estreita relação com o acesso ao conhecimento e à aprendizagem escolar. Esta visão de finalidades educativas e de currículo reconhece e valoriza as práticas socioculturais vividas no seu cotidiano, mas estas devem ser conectadas ao processo de ensino-aprendizagem dos conteúdos. A razão para isso é que, sem se apropriarem dos conteúdos escolares que possibilitam o fortalecimento das capacidades 
intelectuais, as crianças e jovens não terão assegurado o seu direito a se desenvolverem, a formarem novas capacidades de pensamento, a estabelecerem relações entre os conceitos científicos trabalhados pela escola e os conceitos cotidianos vividos nas esferas do local, do comunitário, do global, do planetário. Trata-se, assim, de entender como escola justa aquela que atende a todos por meio de um currículo de formação cultural e científica, articulado pedagogicamente com a diversidade sociocultural, e diretamente enlaçado às condições sociais, culturais e materiais de vida dos alunos.

Os dois últimos posicionamentos comentados têm, em comum, uma aposta no valor da escola pública. No entanto, representam diferentes referenciais de qualidade de ensino os quais, por sua vez, influenciam os modos de conceber atividades no âmbito da escola e das salas de aula. Vê-se que as posições progressistas em educação colocam os objetivos e as formas de funcionamento da escola num campo de tensões: por um lado, a exigência social e democrática de escolarização formal a todas as crianças e jovens; por outro, a necessidade de as escolas se organizarem de forma adequada para o acolhimento da diversidade social e cultural expressa pelas diferenças individuais e sociais entre os alunos. Tal polarização, no entanto, tende a enfraquecer a condição da escola de fazer justiça social principalmente para a população pobre que tem na escola a chance de apropriação do conhecimento teóricoconceitual e de desenvolvimento cognitivo, afetivo e moral. Será viável uma saída pedagógica que aposte na superação desta polarização? Imbernon oferece o entendimento de uma escola capaz de "ajudar os alunos a crescerem e a se desenvolverem como pessoas, facilitando-lhes a aquisição de habilidades básicas tanto de tipo cognoscitivo como de autoconhecimento, de autonomia pessoal e de socialização" e que, para isso, favoreçam "o reconhecimento todas as capacidades, ritmos de trabalho, expectativas, estilos cognoscitivos e de aprendizagem, motivações, etnias, valores culturais de todos os meninos, meninas e adolescentes" (IMBERNÓN, 2000, p. 85). A condição dessa proposta de escola justa é que os educadores aceitem a imprescindibilidade dos conteúdos como referências para o desenvolvimento das capacidades intelectuais dos alunos e, ao mesmo tempo, saibam integrar no currículo as práticas sociais vivenciadas por eles, nas quais está presente a realidade da desigualdade social, acompanhada da diversidade sociocultural. 


\section{Estudos sobre diversidade e sua relevância política e pedagógica. Alguns aportes da pesquisa no Brasil e na América Latina}

Segundo Moehleckle (2009), a expressão "diversidade" traz em si um conjunto múltiplo e complexo de significados, ora destacando a heterogeneidade de culturas, ora associados a movimentos sociais de cunho identitário articulados em torno das "políticas de diferença, ora como sinônimo de multiculturalismo que descreve a pluralidade de culturas numa sociedade ou de educação intercultural" (2009, p. 463-466). Os estudos sobre o tema tendem a remeter o termo diferença à diversidade humana, razão pela qual é frequente o uso dos dois termos um pelo outro. Lázaro, por exemplo, escreve que "diversidade tornou-se um conceito político por excelência e distintos grupos sociais e indenitários advogam o termo para afirmar, positivamente, suas diferenças" (LÁZARO, 2013, p. 265). A diversidade pode ser entendida como conjunto das diferenças, desde que estas sejam tomadas histórica e concretamente. Sacristán ajuda a compreender os termos diferença e diversidade em sua relação com a desigualdade. Para ele, a diferença refere-se à condição da natureza humana, à singularidade de cada ser humano, sendo inseparável de qualquer ação educativa. A diversidade constitui-se dessa condição humana inserida numa determina sociedade. A diversidade, por sua vez, pode converter-se em desigualdade quando particularidades individuais ou grupais levam à privação de direitos (SACRISTÁN, 2008). A diversidade tem, assim, como referência, as diferenças que podem ser naturais ou culturais, enquanto as desigualdades sociais são históricas.

A aplicação desses conceitos na política e na educação tem produzido bastante polêmica em razão de diferentes entendimentos sobre a relação entre igualdade, diferença, desigualdade, e entre universalidade e particularidade, gerando consequências tanto para o planejamento de políticas sociais e educacionais quanto para a pesquisa acadêmica. Barros (2016) escreve que a noção de "igualdade" contrasta com duas outras noções: por um lado, "igualdade" opõe-se a "diferença", por outro, se contradita com "desigualdade". Os estudos no campo do pós-estruturalismo, por sua vez, vêm enaltecendo a atenção à diferença como orientação de lutas políticas e sociais, em contraposição ao princípio universalista produzido na modernidade. A afirmação do direito à diferença e o reconhecimento de multiculturas e múltiplas identidades culturais seriam a base das pautas sociais pela emancipação humana, recusando qualquer caráter de universalidade no ser humano. Conforme Bueno:

O anti-universalismo nega a existência de normas e princípios éticos universais em nome da valorização das particularidades e diferenças entre culturas, comunidades e povos. As normas e regras morais e culturais são 
sempre a de um povo ou comunidade específica e qualquer juízo de valor, comparação ou hierarquia são previamente rejeitados (BUENO, 2012, p. 95).

Esse autor, no entanto, defende que a valorização da diferença é compatível com a universalidade. Somente mediante a universalidade é que o particular pode existir. O acolhimento da diferença significa a possibilidade de estabelecer a distância entre o ser particular em sua contingência e o que o sujeito pode ser em direção à universalidade do ser humano (BUENO, 2012). Posição semelhante é assumida por Santos (2006), que defende a relação dialética entre diferença e igualdade. Ele escreve:

Temos o direito a ser iguais quando a nossa diferença nos inferioriza; e temos o direito a ser diferentes quando a nossa igualdade nos descaracteriza. Daí a necessidade de uma igualdade que reconheça as diferenças e de uma diferença que não produza, alimente ou reproduza desigualdades (2006, p. 470).

A problemática apontada em relação aos entendimentos dos termos igualdade, diferença, desigualdade, se manifesta tanto no âmbito da formulação de políticas públicas para a diversidade quanto no das políticas educacionais e políticas para as escolas. Elas influenciam, também, a pesquisa acadêmica e os formadores de professores, gerando diferentes concepções e práticas no que se refere aos modos de se lidar, pedagógica e didaticamente, com a diversidade social e cultural existente nas escolas. Desse modo, para os propósitos deste artigo, estabelece-se uma necessária distinção entre o discurso político e o discurso pedagógico, uma vez que a relevância pedagógica da atenção à diversidade sociocultural não pode ficar adstrita à sua dimensão política. Ações sociopolíticas formuladas e implementadas no âmbito das políticas públicas em relação à diversidade não substituem ações pedagógico-didáticas realizadas nas escolas e salas de aula. Essas duas instâncias podem ter uma finalidade comum em termos éticos e políticos, mas os modos de realização dessa finalidade são distintos, tal como esclarece Saviani ao argumentar que educação e política são fenômenos inseparáveis, porém, efetivamente distintos entre si (SAVIANI, 2007). O que se está argumentando aqui é que as duas práticas sociais têm, cada uma, sua especificidade. Embora ações sociopolíticas e ações pedagógico-didáticas devam estar articuladas entre si, elas não se identificam umas com as outras, pois a natureza delas é distinta.

A relevância política da diversidade pode ser explicada, em boa parte, pelo aparecimento de fenômenos sociais envolvendo conflitos internacionais, a expansão da globalização econômica, a migração, a afirmação de identidades (RODRIGUES; 
ABRAMOWICZ, 2013), acontecimentos que surgiram em evidência no final dos anos 1990 . Conforme Gomes (2017), é no início do século XXI que o termo diversidade começa a ser objeto de políticas públicas e de algumas pesquisas acadêmicas, junto com o fortalecimento de movimentos sociais de caráter emancipatório. A autora destaca como características desse momento histórico as mudanças tecnológicas, a aproximação de fronteiras via mundo virtual, as imigrações, as desigualdades, a globalização capitalista, os fundamentalismos. Junto a isso, surgem as lutas sociais pela igualdade de direitos expressas em formas de resistência à exploração capitalista, ao racismo, ao machismo, à xenofobia, à LGBTfobia, ao fundamentalismo político e religioso, à intolerância religiosa. Ela escreve:

A relação entre políticas públicas e diversidade está no cerne das mudanças do mundo. [...] A questão das políticas para a diversidade assume um lugar de responsabilidade social e política não somente das cidadãs e cidadãos comuns, mas dos governos e das políticas públicas. E ela vem tencionando cada vez mais não só o setor público, mas, também, o mercado e o mundo privado (GOMES, 2017, p. 10).

Para a autora, a atuação do Estado em relação às desigualdades e diferenças não podem se restringir a políticas de combate à pobreza, à fome ao desemprego, mas voltar-se mais às situações de desigualdade de determinados coletivos sociais. Destaca-se, assim, o protagonismo de movimentos sociais emancipatórios, principalmente de raça, idade, relação campo/cidade, deficiência. Por isso é necessário reeducar o Estado e os governos para a diversidade, de modo a compreenderem que a diversidade é muito mais do que a soma das diferenças ou dos diferentes.

A relevância pedagógica da diversidade humana, por sua vez, está presente nos marcos conceituais da pedagogia e da didática desde quando se reconhece a necessidade de se levar em conta no ensino as características individuais e sociais dos alunos, para o que se requer alguma forma de individualização do ensino de modo a respeitar a diversidade humana. Desse modo, o tema do ensino diferenciado está integrado no movimento da Educação Nova na segunda metade do século XIX, por exemplo, em Claparède e Freinet, que propunham uma escola "sob medida" para o aluno. Ao postular uma educação centrada no aluno, essa visão continua com Dewey, e outros pensadores de algum modo vinculados à Educação Nova. A pedagogia crítica de inspiração marxista, no Brasil dos anos 1980, introduziu a preocupação com as condições sociais de origem dos alunos no ensino, de modo a serem atendidas no processo de conquista de objetivos de aprendizagem por todos os estudantes.

A presença da diferença e da diversidade humana na política e na educação nas últimas décadas trouxe à tona o debate político e acadêmico em torno de diferentes formas de 
abordá-la pedagogicamente na organização escolar e no trabalho dos professores. Para formar um panorama acerca da relação entre diversidade sociocultural e as práticas escolares e docentes realizadas na escola e na sala de aula, foram selecionadas para análise algumas pesquisas em alguns periódicos brasileiros e latino-americanos. O levantamento bibliográfico foi efetivado por meio de uma revisão narrativa, não sistemática, considerando os últimos 10 anos de produção, tendo em vista as seguintes palavras-chave: abordagem pedagógica da diversidade; cultura dos alunos, aprendizagem e escola; diferença na escola; diversidade e escola; diversidade na sala de aula; diversidade, diferença e desigualdade; diversidade sociocultural; diversidade sociocultural e políticas educacionais; diferença cultural e interculturalidades; finalidades educativas escolares e políticas educacionais. O levantamento de pesquisas no Brasil foi realizado em três bases de dados envolvendo produções disponibilizadas pelo Portal de dissertações e teses da CAPES; artigos em periódicos disponíveis no Portal Google Acadêmico e no Portal Scielo. Facultado pela revisão narrativa, foram incluídos no levantamento artigos produzidos antes do período delimitado pelo recorte temporal. Concernente aos países da América Latina, recorremos a colegas pesquisadores estrangeiros que, em sua opinião, indicaram os periódicos mais representativos da pesquisa em educação em seus países. Procedemos ao levantamento de artigos das seguintes revistas: Instituto de Investigaciones em Ciencias de la Educación e Archivo para las Ciencias del Hombre (Argentina), Colombiana de Educación, Pedagogía y Saberes e Educación y Pedagogía (Colômbia) e Perfiles Educativos e Mexicana de Investigación Educativa (México).

Em relação ao Brasil, os autores selecionados (CANEN, 2001; FLEURI, 2003; ORTIZ, 2007; CANDAU, 2012; KATO, 2015; SILVA; REBOLO, 2017) são unânimes em afirmar que os termos multiculturalismo e diversidade sociocultural são polissêmicos, e sua abordagem ganha destaque nacional e internacional articulada a outros temas como diferença e desigualdade. Candau (2012) defende a interculturalidade (multiculturalismo interativo) por considerá-la "mais adequada para a construção de sociedades democráticas que articulem políticas de igualdade com políticas de identidade e reconhecimento dos diferentes grupos culturais" (p. 243). Conforme a autora, a interculturalidade deve estar articulada aos direitos humanos e intermediada pela "construção de práticas pedagógicas comprometidas com a equidade, a democracia e a afirmação do direito à educação e à aprendizagem de toda criança, de todo adolescente, de toda pessoa" (p. 237). Para Canen (2001), “entender multiculturalidade e educação significa vincular educação multicultural a perspectivas de 
transformação da escola e superação dos mecanismos excludentes no interior de suas práticas cotidianas" (p. 212).

Numa avaliação diferente em relação a Candau (2012), Kato aponta que os professores entendem por diversidade sociocultural "as diferentes culturas, a etnia, a língua, a linguagem, a crença, a religião, os valores, as ideologias, o folclore, a classe social, o grau de escolaridade, a forma de se comportar e outros identitários" (KATO, 2015, p. 7). Ela argumenta que quando professores relacionam a diversidade sociocultural na escola com o trabalho pedagógico que realizam, destacam somente os conflitos existentes nas relações dos alunos entre si, destes com os professores, a dificuldade de aprendizagem manifesta pelos alunos e o seu desinteresse pelos estudos. A autora pontua que, na concepção dos professores, a diversidade sociocultural decorre de "consequências da estrutura familiar não convencional, da baixa escolarização dos pais, da negligência destes para com o processo de escolarização e da falta de perspectiva positiva em relação ao futuro dos filhos" (p. 7). A pesquisa de Canen (2001), por sua vez, enfatiza que na visão das professoras, "o conhecimento do aluno concreto como condição para a viabilização de práticas pedagógicas transformadoras [...] não tem lugar no cotidiano da escola" (p. 216).

No mesmo sentido de captar percepções manifestas por professores sobre a diversidade sociocultural na escola, Silva e Rebolo (2017) reforçam o entendimento de que a proposta de educação intercultural implica uma compreensão mais complexa de educação, que se estende para além das estratégias pedagógicas e das relações interpessoais existentes na escola, por exemplo, atividades de aprendizagem que contemplem grupos culturalmente diferentes e os significados elaborados pelas pessoas. Em síntese, a revisão das pesquisas permite identificar conexões entre o contexto social e político da diversidade com práticas pedagógicas. No entanto, em que pese a preocupação explícita destes pesquisadores com a escola e seus professores em relação à diversidade sociocultural, a mediação pedagógica ou se cinge a referências ao âmbito político-social ou a diversidade é vista em suas manifestações particulares.

Em relação aos periódicos de países da América Latina, as abordagens política e pedagógica da diversidade sociocultural são recorrentes. Nos textos selecionados, autores como Lerma (2012), Tapia e Valenti (2016), Flecha e Puigvert (2018), Tevez e Díaz (2019) empregam a expressão "diversidade sociocultural” voltada ora a questões sociais e políticas, ora antropológicas, inserindo nelas o multiculturalismo. Para Guzmán e Guevara, a entrada do multiculturalismo na educação se contrapõe à desvalorização perpetrada por outras narrativas que criaram uma escola homogeneizante e disciplinadora. "As formas que o multiculturalismo 
assume respondem pelas dissonâncias no modo de ver a alteridade, as representações e concepções de cultura em projetos pedagógicos" (2015, p. 23). O multiculturalismo torna-se uma proposta de educação para a alteridade voltada para os direitos do outro, a igualdade e as oportunidades democráticas que visam às relações de respeito entre os grupos socioculturais mediante processos democráticos e dialógicos.

Outros estudos relacionados com a diversidade nas perspectivas multicultural e intercultural salientam a atenção às diferenças humanas e sociais na escola, desde a inclusão de crianças com necessidades especiais, crianças indígenas e crianças pertencentes às populações pobres. $\mathrm{Na}$ diversidade são contemplados, igualmente, os grupos étnicos: indígenas, imigrantes e as pessoas que são vistas como minorias: a população afrodescendente e os homossexuais. Nota-se em alguns artigos a preocupação com a formação do professor para perceberem as diferenças culturais por meio da capacidade de lidar com as diversas culturas ou a interculturalidade (GUZMÁN, 2015; GUZMÁN; GUEVARA, 2015; MORA; MUÑOZ; ZAPATA, 2018).

A diversidade é vista por autores latino-americanos, de modo geral, à condição de minorias, principalmente negros, indígenas, homossexuais, imigrantes e mulheres. Bueno, Sarti e Arnoldi (2018, p. 153-154), ressaltam o termo "minorias" pela ótica das Ciências Sociais, abrangendo "grupos submetidos a processos de estigmatizacão e discriminação que resultam em formas de desigualdade e exclusão sociais". Outros, no entanto, sugerem que, do ponto de vista materialista-dialético, a discriminação e a estigmatizacão produzidas pela condição de pobreza estariam no cerne das desigualdades e injustiças sociais. Para Guzmán (2015), refletir sobre a relação entre interculturalidades e processos educativos remete a formas de intensificação da participação de grupos considerados minorias. Desse modo, desde a década de 1960, discussões teóricas e apostas investigativas têm destacado a necessidade de "se dar voz aos que, historicamente, são marginalizados e silenciados em um mundo em que o estranho e o diferente, quase sempre, são postos sob a lupa da suspeita” (GUZMÁN, 2015, p. 224).

Um dos artigos selecionadas (JULIO-MATURANA et al., 2016), relatando pesquisa com professores do Ensino Fundamental no Chile, constatou a existência de um desencontro cultural e pedagógico na sala de aula como empecilho para a aprendizagem de crianças em situação de pobreza. O estudo mostrou que os professores caracterizam essas crianças como pessoas homogêneas, carentes e com expectativas limitadas em face do processo ensinoaprendizagem. Desse modo, as dificuldades de aprendizagem podem ser explicadas pela discrepância entre as expectativas dos professores e os contextos culturais de onde as crianças 
provêm. Contrapondo-se à ideia de que dificuldades de aprendizagem advêm de desencontros entre as expectativas pedagógicas e a cultura das crianças em situação de pobreza, Mora, Muñoz e Zapata (2018) argumentam que a instituição educacional deve ser dotada de condições "para garantir o bem-estar dos grupos mais desfavorecidos" (p. 149). Para Sierra (2015), é necessário que seja feita a pergunta sobre "qual é o papel da escolarização em relação às práticas culturais que não são reconhecidas nos modelos de escolarização" (p. 122). $\mathrm{O}$ autor adverte que o papel da escolarização pode tanto repetir padrões estabelecidos que tornam obrigatórios determinados conhecimentos e determinadas práticas pedagógicas que prevalecem sobre as diferentes culturas, quanto propor uma escola intercultural que abrange formas de conhecimento próprias ao sistema de conhecimento de cada cultura.

Trazendo a questão da diversidade a partir de uma análise política, Martínez e Diez afirmam que a diversidade cultural pode ser vista como um paradigma histórico e políticonormativo, "incorporado ao gerenciamento de recursos nas prescrições gerais do sistema educacional" (p. 16), na perspectiva da institucionalização da diversidade cultural. Desse modo, a diversidade conquista a adesão dos países latino-americanos com a "introdução paulatina das coordenadas neoliberais que haviam começado a ser experimentadas no laboratório britânico do governo de Margaret Thatcher" (MARTÍNEZ; DIEZ, 2019, p. 17). Para as autoras, a diferença se liga à consolidação do paradigma do "reconhecimento" frente ao esmorecimento dos projetos de emancipação. Assim, a implantação do neoliberalismo e o paradigma da diversidade convergem, como o caso do Peru, Bolívia, México, Colômbia e Argentina nos anos 1990, em que o discurso da diversidade assume um caráter conservador como se fosse um panorama multicultural da sociedade (MARTÍNEZ; DIEZ, 2019).

Os estudos sobre diversidade sociocultural e educação de pesquisadores brasileiros e latino-americanos trazidos aqui são de fundamental importância para a materialização do respeito às diversidades culturais, alcançando as diversas minorias. Entretanto, é preciso realçar que poucas produções se ocuparam do enfoque da diversidade no processo de ensinoaprendizagem na sala de aula e na formação de professores, de modo a captar formas de realização do trabalho pedagógico-didático. A revisão das pesquisas permite concluir que, de modo geral, a abordagem da diversidade sociocultural se circunscreve a particularidades de diferentes grupos étnicos, imigrantes e outras minorias sociais, étnicas e culturais, incluindo pessoas com necessidades educativas especiais. Reafirma-se, assim, a suspeita de que, no campo pedagógico, dirigentes escolares, professores e mesmo pesquisadores estariam entendendo que lidar com a diversidade social e cultural na escola corresponderia a promover práticas de respeito aos "diversos", aos "diferentes". A diversidade cultural seria praticada na 
escola ou pelo apelo aos professores para o seu reconhecimento ou pela utilização de recursos como o trabalho com arte, o esporte e outras atividades de inclusão, ou seja, num currículo paralelo ao currículo comum e não como algo integrado aos conteúdos e ao trabalhopedagógico-didático. Não se trata, obviamente, de censurar os professores que agem assim. As ações socioeducativas de respeito à diversidade decorrentes da abordagem política representam, sem dúvida, avanço social tal como a atenção a pessoas com necessidades educativas especiais, a abordagem das diferenças de gênero em sua ligação com os condicionantes sociais e culturais, as questões da educação sexual, a atenção às minorias sociais, étnicas, culturais. No entanto, na realidade cotidiana de nossas escolas públicas, a questão parece bem mais complexa.

Com efeito, em nosso país, na escola pública comum, diferentemente de países europeus e da América do Norte, a diversidade sociocultural aparece, sim, nas culturas minoritárias, mas muito mais nas diversidades manifestas em razão da origem de classe, das desigualdades sociais, das trajetórias anteriores de escolarização. A população que se inclui na categoria de "grupos mais desfavorecidos", não é a minoria, mas a maioria. Assim, em se tratando da escola pública, o atendimento à diversidade não consiste, em primeiro lugar, em melhorar a situação das minorias étnicas no cotidiano escolar e na sala de aula, mas em contemplar essa melhoria em relação à diversidade de todos os alunos em suas condições sociais, culturais, materiais, em função do acesso aos conhecimentos, incluindo aí os pertencentes a minorias étnicas e culturais. Há, sim, em nossas escolas, minorias sociais, étnicas, culturais, mas, acima de tudo, temos uma maioria pobre cuja necessidade básica é a sobrevivência material, sujeita a todas as consequências decorrentes da desigualdade social e, por isso mesmo, necessitada de ser atendida em seus direitos à educação escolar e, claro, à diferença. Propõe-se, assim, uma abordagem pedagógica da diversidade sociocultural na escola que se distingue de outras que se restringem a oferecer um currículo exclusivamente à medida das identidades culturais. Desse modo, se propõe a dar atenção intencionalmente positiva às diferenças, ao mesmo tempo em que se assegura uma escola unitária, comum, que mantenha ou promova “um mínimo de coesão social e cultural” (FORQUIN, 1993, p. 137).

A proposta considerada aqui, de uma escola socialmente justa, é de um tipo de ensino que assegure a todos os alunos aprender aquilo que é necessário aprender como condição da igualdade entre os seres humanos e, ao mesmo tempo, considerar a diversidade humana e social desses alunos no processo de ensino-aprendizagem, provendo formas de organização que assegurem no ambiente escolar e nas salas de aula os apoios necessários a todos os estudantes para que possam desenvolver suas capacidades intelectuais e sua personalidade 
global. Reitera-se, assim, que finalidade preponderante da escola pública não é, em primeiro lugar, o atendimento à diversidade social e cultural, mas possibilitar formação cultural e científica que, sem ser etnocêntrica, acolha a todos e, ao fazer isso, considera a diversidade, inclusive dos grupos sociais minoritários. Significa inserir no trabalho pedagógico com os alunos as situações sociais, culturais e materiais em que vivem, por exemplo: como vivem seus pais, quais são os traços característicos de sua comunidade, quais são as crenças religiosas das famílias, quais são suas tradições culturais, quais são suas carências materiais, sociais, culturais, quais são os pré-requisitos de escolarização que trazem ou não para a sala de aula, como introduzir no currículo tradições e costumes, que atividades diferenciadas são necessárias para alunos com dificuldades escolares devido a carências de sua escolaridade anterior, dentre outros.

A adoção de um currículo comum e de uma pedagogia que incorpora a diversidade social e cultural nos conteúdos e no trabalho cotidiano dos professores pressupõe um currículo aberto que contempla diferentes culturas. Sacristán (1998) propõe um currículo comum oferecido como orientação geral que contempla critérios científicos de cada área de conhecimento, mas aberto à pluralidade e passível de ser reinterpretado pelos professores em função do contexto em que a escola está inserida.

\section{A abordagem pedagógica da diversidade na teoria do ensino para o desenvolvimento humano. Abrindo um caminho para a escola socialmente justa}

A questão principal anunciada no início deste texto foi por em destaque a relevância da abordagem pedagógica da diversidade sociocultural numa visão de escola socialmente justa, na perspectiva do ensino voltado para o desenvolvimento humano, sem desconsiderar as implicações fortemente políticas da questão da diversidade.

A expressão "escola justa" é utilizada por Dubet (2004) no sentido daquela escola que possa garantir o acesso a bens escolares fundamentais, procura minimizar as desigualdades escolares a fim de que estas não aprofundem ainda mais as desigualdades sociais, que cuida de garantir que os alunos consigam preservar sua dignidade e igualdade com os outros, sem humilhar ou ferir os vencidos, que sejam tratados como sujeitos em desenvolvimento e não apenas como indivíduos engajados em uma competição. Boto realça, no que se refere ao direito de escolarização na atualidade, a exigência de se reconhecer a diversidade social por meio de um currículo aberto que inclua a diversidade dos alunos, suas distintas trajetórias e diferentes pertenças culturais. Ela propõe romper certas amarras simbólicas do conhecimento 
escolar de modo a acatar e conviver com as diferenças, o que leva a "pensar na diversidade sem abdicar, de maneira alguma, do ainda necessário código de universalidade" (BOTO, 2005, p. 793). Sacristán propõe um currículo comum no qual tenham lugar as diferenças, de modo que o universal se componha com o particular. O currículo pode ser, assim, universal e comum, suficientemente aberto para acolher a multiculturalidade e determinadas particularidades existentes na sociedade: "podemos aspirar a um universalismo que compreenda a complexidade e admita a variedade, mas que não seja relativista" (SACRISTÁN, 1998, p. 226). Charlot (2005) propõe que o desafio da escola de hoje é "construir com os alunos a relação com o saber que dá sentido ao saber [...] mas isso deve ser construído no próprio ato do ensino" (2005, p. 119). Segundo o autor, escola democrática é a que possibilita aos jovens adquirir saberes e competências cognitivas e intelectuais e desenvolver sentidos para suas vidas.

Neste tópico final, argumenta-se que as aspirações de escola justa expressas acima pelos autores podem ser viabilizadas pedagogicamente com os princípios da teoria para o desenvolvimento humano de V. Davydov (1988a) e as contribuições de M. Hedegaard (2004) e Hedegaard e Chaiklin (2005). Davydov desenvolveu a teoria do ensino desenvolvimental fundamentado no materialismo histórico e dialético e no pensamento de Vygotsky, em que a questão central da pedagogia é a relação entre educação e desenvolvimento humano. Desse modo, o aspecto central do processo de ensino-aprendizagem é que as várias formas de interação social professor-alunos e entre alunos impulsionam e ativam processos internos de desenvolvimento, visando a formação da personalidade. Essas interações ocorrem em atividades de estudo organizadas pelo professor, as quais visam mobilizar capacidades intelectuais dos alunos tendo em vista a formação do pensamento teórico-conceitual e, com isso, o desenvolvimento da consciência humana. $\mathrm{O}$ pensamento por conceitos diz respeito ao modo dialético de pensar, ou seja, compreender os objetos de conhecimento desde sua origem e desenvolvimento histórico, em seus diversos nexos sociais, o que proporciona aos alunos criticidade e autonomia perante os conhecimentos. É a formação cultural e científíca que possibilita ao ser humano a interiorização dos modos historicamente determinados e culturalmente organizados de compreensão da realidade e propicia autonomia aos sujeitos para lidarem com a realidade e consigo mesmos. Ainda segundo Davydov, na organização da atividade de estudo, a aprendizagem de conteúdos atinge melhor o desenvolvimento da personalidade quando existe uma relação entre o conteúdo e os motivos do estudante para aprender, o que implica a necessidade de adequar os conteúdos às disposições internas e interesses dos alunos (DAVÍDOV, 1988b; DAVYDOV, 1999; LIBÂNEO; FREITAS, 2013, 
LIBÂNEO, 2016; SILVA, 2020). A teoria do ensino desenvolvimental tem sua centralidade, portanto, na atuação do ensino no desenvolvimento das capacidades humanas.

Por sua vez, Hedegaard elabora uma teoria em que conhecimento escolar, desenvolvimento do pensamento e participação dos alunos em práticas socioculturais estão interligados, oferecendo um modelo pedagógico em que se articulam tradições e práticas culturais, organização da atividade de ensino e vivências sociais concretas das crianças. A proposta de um ensino centrado na formação do pensamento teórico-conceitual estreitamente vinculado às condições sociais, culturais e materiais concretas dos alunos foi denominada abordagem do ensino radical-local. Este vínculo requer uma metodologia de ensino em que o domínio dos conceitos científicos interage com os conceitos cotidianos dos alunos, razão pela qual a autora realça o papel das práticas socioculturais na organização do ensino. Para ela, as práticas socioculturais e institucionais das quais os alunos participam na família, na comunidade local, na vida cotidiana são, também, determinantes na apropriação do conhecimento e capacidades, na constituição da identidade pessoal, sendo que elas são caracterizadas na escola tanto como contexto da aprendizagem quanto como conteúdo (HEDEGAARD, 2004). Isto quer dizer que o desenvolvimento do pensamento de um aluno que ocorre no processo de apropriação dos conteúdos científicos precisa estar articulado com as formas de conhecimento das quais participa na sua vida cotidiana. É nessas práticas que se manifestam a diversidade social e cultural, as redes de conhecimento, as particularidades culturais, as experiências e vivências que formam a subjetividade dos alunos. É o meio pedagógico de articulação entre conhecimentos científicos e conhecimentos cotidianos com base no qual os professores realizam o duplo movimento no ensino. Para isso, com base no conceito de zona de desenvolvimento próximo criado por Vygotsky, é proposta a abordagem do duplo movimento no ensino, ou seja, situações didáticas que possibilitam ao professor fazer interagir o conhecimento teórico-conceitual ao conhecimento pessoal vivido pelos alunos em suas práticas cotidianas na família e na comunidade, e utilizando essa conexão para mobilizar os motivos dos alunos para as diferentes matérias. Desse modo, o conteúdo torna-se significativo para a criança e motivador para a compreensão tanto dos princípios teóricos da matéria quando dos problemas da prática local e cotidiana. Escrevem Hedegaard e Chaiklin (2005) a esse respeito:

Nesta forma de ensino, o conhecimento teórico-conceitual e o conhecimento local podem tornar-se integrados, de modo que o conhecimento teóricoconceitual possa enriquecer os conhecimentos pessoais da criança, usando-o na compreensão da prática local cotidiana. Na perspectiva radical-local, o professor parte da compreensão da criança e as orienta para tarefas e 
problemas ligados ao conteúdo que, assim, torna-se significativo para a criança e motivador para a compreensão tanto dos princípios teóricos da matéria quando dos problemas da prática local e cotidiana (HEDEGAARD; CHAIKLIN, 2005, p. 81).

É substanciosa, pois, a contribuição de Hedegaard no sentido de promover a função da escola de trabalhar com o conhecimento teórico-conceitual em conexão com as práticas culturais nas diferentes instituições da sociedade.

\section{Considerações finais}

O conteúdo deste artigo trouxe para discussão o tema das finalidades educativas escolares e sua conexão com a diversidade sociocultural tendo em vista sua abordagem pedagógica e tendo como pano de fundo uma visão de escola socialmente justa. A atividade escolar foi apresentada como prática social visando à formação e desenvolvimento de seres humanos na dinâmica das relações sociais, em condições socioculturais e institucionais concretas, concebendo-se, portanto, como sua finalidade prioritária e preponderante o desenvolvimento das capacidades humanas para a vida em sociedade. Por sua vez, a diversidade foi apresentada como característica constitutiva do ser humano, portanto, inerente àquilo que os seres humanos têm de universal. Desse modo, a atividade escolar implica formas de individuação e diferenciação pedagógica, uma vez que os educadores lidam com sujeitos sociais concretos, singulares e irrepetíveis, com necessidades próprias, interesses, motivos. Então, nenhum professor pode ensinar sem levar em conta a diversidade humana. Considerou-se, assim, neste texto, o entendimento de que a finalidade máxima da educação escolar é o desenvolvimento de todas as dimensões do ser humano naquilo que ele tem de universal, cuja realização no ensino implica considerar a diversidade sociocultural dos alunos, enquanto constituinte de uma visão mais ampla das finalidades educativas. Nisso consiste a consumação de propósitos em relação à escola socialmente justa. O texto é finalizado com o entendimento de que as escolas e professores devem assumir as implicações éticas e políticas da atenção à diversidade sociocultural, no entanto, seus efeitos educativos não podem prescindir da sua abordagem pedagógica, ou seja, sua inserção nos próprios conteúdos escolares e nas metodologias de ensino.

Post-scriptum - A escrita deste texto foi concluída 70 dias após a interrupção do funcionamento de escolas e instituições de ensino superior em razão da pandemia provocada pelo novo coronavírus. Aulas presenciais foram suspensas em todos os estados brasileiros desde a segunda quinzena de março de 2020, trazendo aos professores das escolas em todos 
os níveis e, em especial, em escolas públicas de Educação Básica, uma nova realidade, o ensino em ambiente virtual, e a polêmica de cunho social e pedagógico em torno da pertinência e do papel das aulas online numa visão de ensino emancipatório e voltado para o desenvolvimento humano. Embora se trate de um momento singular e transitório na vida da sociedade, a pandemia fez antecipar questões de impacto em relação a finalidades educativas escolares e a formas pedagógicas de implementá-las. Até que ponto a tecnologia pode ser instituída como forma predominante de aprendizagem, como, aliás, já vem ocorrendo em muitas instituições privadas de ensino? Quais são as consequências sociais, psicológicas e pedagógicas da educação domiciliar e do ensino remoto? Como fica a socialização das crianças em ambientes virtuais de aprendizagem? Quais são os limites sociais, psicológicos e pedagógicos da educação a distância, na perspectiva de um ensino voltado para o desenvolvimento humano? Enfim, persiste a desafiante pergunta trazida neste texto: para que servem as escolas?

\section{REFERÊNCIAS}

ALGEBALE, E. Escola pública e pobreza no Brasil: a ampliação para menos. Rio de Janeiro: FAPERJ/Lamparina, 2009.

BARROS, J. A. Igualdade e diferença: construções históricas e imaginárias em torno da desigualdade humana. Petrópolis: Vozes, 2016.

BOTO, C. Educação escolar como direito humano de três gerações: identidades e universalismos. Educação e Sociedade [online], v. 26, n. 92, p.777-798, 2005.

BUENO, S. F. Quando a diferença é dogma: reflexões sobre a universalidade e o relativismo. In: ZUIM, A.; LASTORIA, L. A. C. N.; GOMES, L. R. Teoria crítica e formação cultural: aspectos filosóficos sócio-políticos. Campinas: Autores Associados, 2012.

BUENO; B. O.; SARTI, F. M.; ARNOLDI, E. S. Aportes de la etnografía educativa al estudio de minorías/mayorías. Pedagogía y Saberes, Universidad Pedagógica Nacional, n. 49, p. 51164, 2018. Disponível em: https://revistas.pedagogica.edu.co/index.php/PYS. Acesso em: 10 abr. 2020.

CANDAU, V. M. F. Diferenças culturais, interculturalidade e educação em direitos humanos. Educ. Soc., Campinas, v. 33, n. 118, p. 235-250, jan./mar. 2012.

CANDAU, V. M. (Org.). Diferenças culturais e educação: construindo caminhos. Rio de Janeiro: 7 Letras, 2011.

CANEN, A. Universos culturais e representações docentes: subsídios para a formação de professores para a diversidade cultural. Educ. Soc. [online], v. 22, n. 77, p. 207-227, 2001. 
Disponível em: https://www.scielo.br/scielo.php?pid=S0101-

73302001000400010\&script=sci_abstract\&tlng=pt. Acesso em: 10 abr. 2020.

CHARLOT, B. Relação com o saber, formação de professores e globalização. Porto Alegre: Artmed, 2005.

DAVYDOV, V. V. Problems of developmental teaching: the experience of theoretical and experimental psychological research. Soviet Education, n. 8-10, 1988a.

DAVÍDOV, V. V. La enseñanza escolar y el desarrollo psíquico. Moscú: Editorial Progreso, 1988b.

DAVYDOV, V. V. O que é a atividade de estudo? Revista Escola inicial, Moscou, n. 7, 1999.

DUBET, F. o que é uma escola justa? Cadernos de Pesquisa, v. 34, n. 123, p. 539-555, set./dez. 2004.

EVANGELISTA, O. (Org.). O que revelam os "slogans" na política educacional. Araraquara: Junqueira \& Marin Editores, 2014.

EVANGELISTA, O.; SHIROMA, E. O. Educação para o alívio da pobreza: novo tópico da agenda global. Revista de Educação, PUC Campinas, v. 20, p. 43-54, 2006.

FIALA, R. Educational ideology and the school curriculum. In: BENAVOT, A.; BRASLAVSKY, C. (Eds.). School knowledge in comparative and historical perspective: changing curricula in primary and secondary education. Hong Kong: Springer, 2007. p. 1534.

FLECHA, R.; PUIGVERT, L. Formación del profesorado en las comunidades de Aprendizaje. Revista Colombiana de Educação, n. 48, p. 12-36, 2018. Disponível em: https://revistas.pedagogica.edu.co/index.php/RCE/issue/archive. Acesso em: 17 abr. 2020.

FLEURI, R. M. Intercultura e educação. Revista Brasileira de Educação, n. 23. p. 16-35, maio/jun./jul./ago. 2003. Disponível em: https://www.scielo.br/scielo.php?pid=S141324782003000200003\&script=sci_abstract\&tlng=pt. Acesso em: 10 abr. 2020.

FORQUIN, J. C. Escola e cultura: as bases sociais e epistemológicas do conhecimento escolar. Porto Alegre: Artes Médicas, 1993.

GARCIA, R. M. C. Para além da "inclusão": crítica às políticas educacionais contemporâneas. In: EVANGELISTA, O. (Org.). O que revelam os "slogans" na política educacional. Araraquara: Junqueira \& Marin Editores, 2014.

GOMES, N. N. Políticas públicas para a diversidade. Sapere aude, Belo Horizonte, v. 8, n. 15, p.7-22, jan./jun. 2017.

GUZMÁN, E. C.; GUEVARA, S. P. G. La interculturalidad: principio o fin de la utopía? Revista Colombiana de Educação, n. 69, p. 17-43, 2015. Disponível em:

https://revistas.pedagogica.edu.co/index.php/RCE/issue/archive. Acesso em: 15 abr. 2020. 
GUZMÁN, G. L. Interculturalidad crítica y educación: un encuentro y una apuesta. Revista Colombiana de Educação, n. 69, p. 223-235, 2015. Disponível em:

https://revistas.pedagogica.edu.co/index.php/RCE/issue/archive. Acesso em: 08 abr. 2020.

HEDEGAARD, M. A Cultural-historical approach to learning in classrooms. Outlines.

Critical Practice Studies, v. 6, n. 1, 2004.

HEDEGAARD, M.; CHAIKLIN, S. Radical-local teaching and learning: a culturalhistorical approach. Aarhus: Aarhus University Press, 2005.

IMBERNÓN, F. Amplitude e profundidade do olhar: a educação ontem, hoje e amanhã. In: IMBERNÓN, F. (Org.). A educação no século XXI: os desafios do futuro imediato. Porto Alegre: Artes Médicas, 2000.

JULIO-MATURANA, C. et al. Desencuentro cultural en el aula: una barrera al aprendizaje de niños y niñas en situación de pobreza. Revista Mexicana de Investigación Educativa RMIE, v. 21, n. 68, p. 71-94, 2016. Disponível em:

https://www.redalyc.org/revista.oa?id=140. Acesso em: 20 abr. 2020.

KATO, A A. G. Diversidade sociocultural: concepções de professores de uma escola pública do estado de mato grosso. 2015. 152 f. Dissertação (Mestrado em Educação) Universidade do Estado de Mato Grosso, Cáceres, MT, 2015.

LEHER, R. Da ideologia do desenvolvimento à ideologia da globalização: a educação como estratégia do Banco Mundial para o alívio da pobreza. 1998. Tese (Doutorado) Universidade de São Paulo, São Paulo, 1998.

LENOIR, Y. et al. (Orgs.). Les finalités éducatives scolaires: clarifications conceptuelles. In: LENOIR, Y., ADIGÜZEL, O., LENOIR, Y., LIBÂNEO, J. C. et TUPIN, F. (Eds.). Les finalités éducatives scolaires: pour une étude critique des approches théoriques, philosophiques et idéologiques. Saint-Lambert: Groupéditions Éditeurs, 2016.

LERMA, K. E. La construcción de la diferencia en la respuesta educativa actual. Perfiles Educativos, v. XXXIV, n. 136, p. 138-148, 2012. Disponível em:

http://www.iisue.unam.mx/perfiles/numeros/2017/157. Acesso em: 18 abr. 2020.

LESSARD, C.; MEIRIEU, P. (Eds.). L'obligation de résultats en éducation: évolutions, perspectives et en jeux internationaux. Bruxelles: Groupe De Boeck, 2005.

LIBÂNEO, J. C. Finalidades educativas escolares em disputa, currículo e didática. In: LIBÂNEO, J. C.; ROSA, S. V.; SUANNO, M. V. R.; ECHALAR, A. D. L. (Orgs.). Em defesa do direito à educação escolar: didática, currículo e políticas educacionais em debate. Goiânia: CEPED/Espaço Acadêmico, 2019.

LIBÂNEO, J. C. Políticas educacionais neoliberais e escola: uma qualidade de educação restrita e restritiva. In: LIBÂNEO, J. C.; FREITAS, R. A. M. M. (Orgs.). Políticas educacionais neoliberais e a escola pública: uma qualidade restrita de educação. Goiânia: Espaço Acadêmico, 2018. p. 45-88. 
LIBÂNEO, J. C. Finalités et objectifs de l'éducation et action des organismes internationaux au Brésil. In: LENOIR, Y. et al. (Orgs.). Les finalités éducatives scolaires: pour une étude critique des approches théoriques, philosophiques et idéologiques. Saint-Lambert (Quebec, Canadá): Groupéditions Editeurs, 2016.

LIBÂNEO, J. C. Internacionalização das políticas educacionais: elementos para uma análise pedagógica de orientações curriculares para o ensino fundamental e de propostas para a escola pública. In: SILVA, M. A. da; CUNHA, C. da (Org.). Educação básica: políticas, avanços, pendências. Campinas: Autores Associados, 2014.

LIBÂNEO, J. C. O declínio da escola pública brasileira: apontamentos para um estudo crítico. In: LOMBARDI, J. C.; SAVIANI, D. (Orgs.). História, educação e transformação: tendências e perspectivas para a educação pública no Brasil. Campinas: Autores Associados, 2011. p. 157-186.

LIBÂNEO, J. C. Didática na formação de professores: entre a exigência democrática de formação cultural e científica e as demandas das práticas socioculturais. In: SANTOS, A.; SUANNO, M. V. Didática e formação de professores: novos tempos, novos modos de aprender e ensinar. Porto Alegre: Sulina, 2013.

LIBÂNEO, J. C.; FREITAS, R. A. M. M. (Orgs.). Políticas educacionais neoliberais e escola pública: uma qualidade restrita de educação escolar. Goiânia: Espaço Acadêmico, 2018.

LIBÂNEO, J. C; FREITAS, R. A. M. M. Vasily Vasilyecich Davyudov: a escola e a formação do pensamento teórico-científico. In: Longarezi, A. M.; PUENTES, R. V. (Orgs.). Ensino desenvolvimental: vida, pensamento e obra dos principais representantes russos. Uberlândia: EDUFU, 2013.

MARTÍNEZ, L. V.; DIEZ, M. L. La enseñanza de la diversidad cultural en la formación docente: cinco dilemas para el debate. Revista del Instituto de Investigaciones em Ciencias de la Educación, n. 45, p. 15-30, jan./jun. 2019. Disponível em:

http://revistascientificas.filo.uba.ar/index.php/iice. Acesso em: 25 abr. 2020.

MOEHLECKLE, S. As políticas de diversidade na educação no Governo Lula. Cadernos de Pesquisa, v. 39, n. 137, p. 461-487, maio/ago. 2009.

MORA, B. A. M.; MUÑOZ, J. H. O.; ZAPATA, S. P. Política de cobertura y de calidad: desafíos del docente que atiende a la diversidad educativa. Perfiles Educativos, v. XL, n. 161, p. 147-160, 2018. Disponível em: http://www.iisue.unam.mx/perfiles/numeros/2017/157. Acesso em: 19 abr. 2020.

NODDINGS, N. Aims, goals and objectives. Encounters on Education, n. 8, p. 7-15, 2007.

ORTIZ, R. Anotações sobre o universal e a diversidade. Revista Brasileira de Educação, v. 12, n. 34, jan./abr. 2007. Disponível em:

https://www.scielo.br/pdf/rbedu/v12n34/a02v1234.pdf. Acesso em: 10 abr. 2020. 
PESSONI, L. M L. Internacionalização das políticas educacionais, finalidades educativas escolares e qualidade de ensino: a reforma educativa no estado de Goiás. 2017. 206f. Tese (Doutorado em Educação) - Pontifícia Universidade Católica de Goiás, Goiânia, 2017.

RODRIGUES T. C.; ABRAMOWICZ, A. O debate contemporâneo sobre a diversidade e a diferença nas políticas e pesquisas em educação. Educação e Pesquisa, São Paulo, v. 39, n. 1, p. 15-30, jan./mar. 2013.

SACRISTÁN, J. G. A construção do discurso da diversidade e as suas práticas. In: PARASKEVA, J. M. (Org.). Educação e poder abordagens críticas e pós-estruturais. Mangualde: Edições Pedagogo, 2008.

SACRISTÁN, J. G. Poderes inestables em educación. Madrid: Morata, 1998.

SANTOS, B. S. A gramática do tempo: para uma nova cultura política. São Paulo: Cortez, 2006.

SAVIANI, D. Escola e Democracia. São Paulo: Autores Associados 2007.

SIERRA, J. A. F. Ciclos de vida como principio activo hacia una escolarización intercultural. Revista Colombiana de Educación, n. 69, p. 121-133, 2015. Disponível em: https://revistas.pedagogica.edu.co/index.php/RCE/issue/archive. Acesso em: 9 abr. 2020.

SILVA, E. A atividade de estudo no Ensino Fundamental conforme a teoria do ensino desenvolvimental de V. Davydov e contribuições de M. Hedegaard: um experimento didático em ciências. 2020. 282 f. Tese (Doutorado em Educação) - Pontifícia Universidade Católica de Goiás, Goiânia, 2020.

SILVA, V. A.; REBOLO, F. A educação intercultural e os desafios para a escola e para o professor. Interações, Campo Grande, v. 18, n. 1, p. 179-190, jan./mar. 2017.

TAPIA G. L. A.; VALENTI, G. Desigualdad educativa y desigualdad social en México: nuevas evidencias desde las primarias generales en los estados. Perfiles Educativos, v. XXXVIII, n. 151, p. 32-54, 2016. Disponível em:

http://www.iisue.unam.mx/perfiles/numeros/2017/157. Acesso em: 18 abr. 2020.

TEVEZ, E.; DÍAZ, S. D. La interculturalidad en un aula de primaria: tensiones durante el tratamiento de la categoría inmigrante. Revista del Instituto de Investigaciones em Ciencias de la Educación, n. 45, p. 77-90, jan./jun. 2019. Disponível em:

http://revistascientificas.filo.uba.ar/index.php/iice. Acesso em: 25 abr. 2020.

UNESCO. Declaração mundial sobre educação para todos e plano de ação para satisfazer as necessidades básicas de aprendizagem. (Jomtien, Tailândia). Paris: Unesco, 1990. Disponível em: http://www.unesco.org/education/nfsunesco/pdf/JOMTIE_F.PDF. Acesso em: 04 abr. 2010. 


\section{Como referenciar este artigo}

LIBÂNEO, J. C.; SILVA, E. Finalidades educativas escolares e escola socialmente justa: a abordagem pedagógica da diversidade social e cultural. Revista on line de Política e Gestão Educacional, Araraquara, v. 24, n. esp. 1, p. 816-840, ago. 2020. e-ISSN:1519-9029. DOI: https://doi.org/10.22633/rpge.v24iesp1.13783

Submetido em: 20/02/2020

Revisões requeridas: $30 / 04 / 2020$

Aprovado em: 28/06/2020

Publicado em: 01/08/2020 